\title{
STATUS AND TREND OF HIV/AIDS EPIDEMIC IN NEPAL
}

\author{
Joshi A B, Banjara M R*, Karki Y B*, Subedi B K**, Sharma M
}

\section{ABSTRACT}

The main objective of this study is to review the HIV/AIDS status and trend in Nepal. The design of the study was retrospective in nature. Review was made of published and unpublished documents during the period 1988 to 2004. Year-wise data indicates that the cases of HIV/AIDS have been increased sharply since mid 1990s. In 1992, more than double numbers of new cases were reported than the formerly reported cumulative cases. The latest cumulative HIV/AIDS cases as of May 2004 were reported as 747 cases of AIDS and 3765 cases of HIV infections. Among total HIV/AIDS cases, clients of sex workers (57.8 percent) were predominant followed by sex workers (13.9 percent) and injecting drug users (15.6 percent). Similarly, others included housewives (10.6 percent), children (1.8 percent) from vertical transmission and blood or organ recipients $(0.2$ percent). Male cases (73.0 percent) were found predominant than female cases (27.0 percent). HIV prevalence among risk group population was found highest in injecting drug users (38.4 percent) followed by Female Sex Workers (4.1 percent) and migrants (3.0 percent). The risk population and HIV/AIDS prevalence has been found sharply increasing after mid 1990s. The increasing trend of the disease certainly has given pressure to focus on the use of comprehensive targeted intervention programs in risk group sub-populations.

\section{Key Words: HIV/AIDS, Trend, Risk populations, Prevalence.}

\section{INTRODUCTION}

Globally, only a small number of HIV infections are estimated to have occurred during the late 1970s and early 1980s. During the 1990s, HIV prevalence increased remarkably in subSaharan Africa. HIV has been well established in Asia for many years. The HIV/AIDS epidemic is spreading rapidly in all South Asian countries. India has the single largest proportion of HIV positive cases within its border, second globally to South Africa. Over 4 million estimated HIV infections are existing within the region and about 13,000 AIDS cases have been reported by the year $2000 .{ }^{1}$ The first case of AIDS in Nepal was reported in 1988. By mid 1990s, Nepal has entered the 'concentrated epidemic' stage with consistent HIV prevalence in Female Sex Workers (FSWs), Injecting Drug Users (IDUs) and migrants. There were around 60,018 people living with HIV/AIDS and 2,598 AIDS related deaths by 2002. The HIV prevalence is estimated around 0.5 percent in the general adult population. ${ }^{2,3}$ There is high potential for and increased spread of HIV from high-risk groups to the general population. The heterosexual contact has been incriminated as predominant mode of transmission. Risk behaviors are wide spread among female sex workers, their clients, injecting drug users, labor migrants and youth., 4,6

* Institute of Medicine, Tribhuvan University Teaching Hospital, Maharajgunj, Kathmandu, Nepal.

** Population Health and Development Group, Kathmandu, Nepal.

*** National Center for AIDS and STD Control, Dept. of Health Services, Ministry of Health, Kathmandu, Nepal.

Address for correspondence : Dr. Anand Ballabh Joshi

Institute of Medicine, Tribhuvan University Teaching Hospital, Maharajgunj, Kathmandu, Nepal.

Email: research@healthnet.org.np 
Increasing level of sexually transmitted infections (STIs) has been reported over few years. Social stigma and discriminations make it difficult for the people living with HIV/AIDS and high-risk groups to practice safer sex, undergo testing and seek treatment and care if infected. HIV/AIDS would have the impact of increasing poverty, negative impact on socioeconomic development and the loss of productive life.

This review was made with an objective to study the status and trend of HIV/AIDS and the prevalence of HIV infections among high-risk sub populations in Nepal.

\section{METHODOLOGY}

Retrospective review of various published and unpublished documents was made. The analysis was made with a view to know the prevalence over the years and the prevalence among sub-populations having risk behaviors. The HIV/AIDS cases have also been analyzed by sex and age distribution.

\section{RESULTS}

Year-wise data indicates that the cases of HIV/AIDS have increased sharply since mid 1990s. In 1992, more than double numbers of new cases was reported than the formerly reported cumulative cases. The National Center for AIDS and STD Control (NCASC), Ministry of Health (MoH) collects HIV/ AIDS data regularly from its sentinel surveillance sites and publishes data every three months. The latest cumulative HIV/ AIDS cases as of May 2004 were reported as 747 cases of AIDS and 3765 cases of HIV infections (Table I).

Among total HIV/AIDS cases, clients of sex workers (57.8 percent) were predominant followed by injecting drug users (15.6 percent) and sex workers (13.9 percent). Similarly, others included housewives (10.6 percent), children (1.8 percent) from vertical transmission and blood or organ recipients $(0.2$ percent). Data shows that male cases ( 73 percent) were predominant than female cases ( 27 percent).

The overall HIV infection rate was 0.5 percent in adult population between the ages 15-49. It is estimated that 68270 adults aged 15-49 years are living with HIV/AIDS. Among reported HIV/AIDS cases by May 2004, 15-49 age groups were found more infected than others. Among them 30-39 age group were predominant (Table III).

Table I : Year-wise detection of HIV/AIDS cases (National figure)

\begin{tabular}{c|cc|c}
\hline Years & $\begin{array}{c}\text { HIV Positive } \\
\text { (New cases) }\end{array}$ & $\begin{array}{c}\text { Cumulative } \\
\text { HIV/AIDS cases }\end{array}$ & AIDS Cases \\
\hline 1988 & 4 & 4 & 2 \\
\hline 1989 & 2 & 6 & 0 \\
\hline 1990 & 5 & 11 & 2 \\
\hline 1991 & 26 & 37 & 5 \\
\hline 1992 & 77 & 114 & 5 \\
\hline 1993 & 81 & 195 & 10 \\
\hline 1994 & 40 & 235 & 16 \\
\hline 1995 & 110 & 345 & 31 \\
\hline 1996 & 88 & 480 & 100 \\
\hline 1997 & 152 & 969 & 54 \\
\hline 1998 & 225 & 1189 & 54 \\
\hline 1999 & 265 & 1411 & 85 \\
\hline 2000 & 370 & 1807 & 84 \\
\hline 2001 & 516 & 2131 & 80 \\
\hline 2002 & 467 & 2598 & 43 \\
\hline 2003 & 505 & 3103 &
\end{tabular}

Table II : Cumulative HIV infection by sub-group and sex by May 2004

\begin{tabular}{lcc|c|c}
\hline \multicolumn{1}{c}{ Sub-groups } & Male & Female & Total & \% \\
\hline Sex workers & -- & 524 & 524 & 13.9 \\
\hline Clients of sex workers & 2,117 & 61 & 2178 & 57.8 \\
\hline Housewives & -- & 400 & 400 & 10.6 \\
\hline Blood or organ recipients & 6 & 2 & 8 & 0.2 \\
\hline Injecting drug users & 583 & 3 & 586 & 15.6 \\
\hline Children & 42 & 27 & 69 & 1.8 \\
\hline \multicolumn{1}{c}{ Total (\%) } & $\mathbf{2 7 4 8}$ & $\mathbf{1 0 1 7}$ & $\mathbf{3 7 6 5}$ & $\mathbf{1 0 0 . 0}$ \\
\hline
\end{tabular}


Table III : Cumulative HIV infection by age group as of May 2004

\begin{tabular}{c|cc|c|cc|c}
\hline \multirow{2}{*}{$\begin{array}{c}\text { Age group } \\
\text { (Years) }\end{array}$} & \multicolumn{3}{|c|}{ Number } & \multicolumn{3}{c}{ Percent } \\
\cline { 2 - 7 } & Male & Female & Total & Male & Female & Total \\
\hline $0-4$ & 24 & 19 & 43 & 0.87 & 1.87 & 1.14 \\
\hline $5-9$ & 18 & 9 & 27 & 0.66 & 0.88 & 0.72 \\
\hline $10-14$ & 9 & 6 & 15 & 0.33 & 0.59 & 0.40 \\
\hline $15-19$ & 149 & 162 & 311 & 5.42 & 15.93 & 8.26 \\
\hline $20-24$ & 553 & 273 & 826 & 20.12 & 26.84 & 21.94 \\
\hline $25-29$ & 723 & 257 & 980 & 26.31 & 25.27 & 26.03 \\
\hline $30-39$ & 1003 & 234 & 1237 & 36.50 & 23.01 & 32.86 \\
\hline $40-49$ & 225 & 51 & 276 & 8.19 & 5.01 & 7.33 \\
\hline $50 ?$ & 44 & 6 & 50 & 1.60 & 0.59 & 1.33 \\
\hline Total & $\mathbf{2 7 4 8}$ & $\mathbf{1 0 1 7}$ & $\mathbf{3 7 6 5}$ & $\mathbf{1 0 0 . 0 0}$ & $\mathbf{1 0 0 . 0 0}$ & $\mathbf{1 0 0 . 0 0}$ \\
\hline
\end{tabular}

Table IV : Estimates of population at risk (15-49) and People Living with HIV/AIDS, 2003, Nepal

\begin{tabular}{|c|c|c|c|}
\hline Groups at risk of HIV/AIDS & $\begin{array}{c}\text { Population } \\
\text { at risk, 2003 }\end{array}$ & $\begin{array}{c}\text { HIV } \\
\text { prevalence \% }\end{array}$ & $\begin{array}{c}\text { People Living } \\
\text { with HIV/AIDS }\end{array}$ \\
\hline Injecting Drug Users (IDUs) & 22,050 & 38.38 & 8,463 \\
\hline Female Sex Workers (FSWs) & 25,550 & 4.05 & 1,035 \\
\hline Migrants & 820,000 & 3.00 & 24,600 \\
\hline Clients of FSWs & 521,500 & 2.07 & 10,795 \\
\hline Man Sex with Man (MSM) & 116,050 & 0.75 & 870 \\
\hline Prison population & 7,000 & 0.75 & 53 \\
\hline Transfusion recipients & 102,998 & 0.44 & 453 \\
\hline Partners of high risk males & 865,566 & 0.27 & 2,337 \\
\hline Uniformed services & 130,000 & 0.22 & 286 \\
\hline Pregnant women & 775,373 & 0.20 & 1,551 \\
\hline Adolescents and youth & $6,542,799$ & 0.12 & 7,851 \\
\hline Rest of population & $4,995,600$ & 0.20 & 9,991 \\
\hline Total $10-49$ years age group & $14,924,486$ & 0.46 & 68,285 \\
\hline Total 15-49 years age group & $11,982,475$ & 0.57 & 68,270 \\
\hline
\end{tabular}

HIV prevalence among risk group populations was found highest in injecting drug users ( 38.4 percent) followed by street based female sex workers (16.3 percent) and partners of injecting drug users (14.4 percent).

The prevalence of HIV/AIDS among injecting drug users was found sharply increased in Kathmandu after 1995. It was 1.57 percent in 1991 and 2.56 percent in 1992 respectively. In 1997 and 2002, it was 50 and 68 percent respectively. In Pokhara and Eastern Terai, prevalence rate was 22 percent and 35 percent in 2003 respectively. HIV prevalence among female sex workers in Kathmandu valley was less than one percent in 1990. It was sharply gone up 9 percent in 1996/1997 and 15.7 percent in 2001. In Terai highway districts HIV prevalence among female sex workers was 3.9 percent in 1999 and slightly decreased to 3 percent in 2003. HIV prevalence among clients of female sex workers was 1.5 percent in sixteen Terai highway districts in 1999, which was 1.75 percent in 2003. Few studies conducted among migrants to Indian cities revealed prevalence rate 10 percent in Doti and 6-8 percent in Achham and Kailali.
Altogether, 12 risk groups have been identified. ${ }^{7}$ The size of each group and also estimated HIV/AIDS cases people living with HIV/AIDS (PLWHA) has been given in Table 4. It has been considered that the whole population of Nepal aged 1049 is at risk of HIV and the risk population sub-group given in table 4 is mutually exclusive. For 2003 , the population was linearly interpolated between 2001 and 2005 total figures. ${ }^{8}$

The total newly estimated People Living with HIV/AIDS (PLWHA), as shown above in Table IV, comes to 68,270 for 15-49 age groups and if 10-49 is included the People Living with HIV/AIDS size becomes 68,285 . HIV prevalence among the $15-49$ population is estimated at 0.57 based on the new estimates of People Living with HIV/AIDS.

\section{DISCUSSION}

Distribution of high-risk populations and HIV prevalence is not uniform within certain administrative and ecological region of Nepal. It is rather associated with the extension of highways, mobility status and urbanization. ${ }^{9}$ 
The first national strategic framework on HIV/AIDS in Nepal was developed in 1997 by National Center for AIDS and STD Control. ${ }^{10}$ Due to lack of operational strategies, it was not translated into a national program. "National HIV/AIDS strategy 2002-2006" was also endorsed by National AIDS Council chaired by the PrimeMinister. The strategy clearly identified five priority areas including prevention of sexually transmitted infections (STIs) and HIV infection among the most vulnerable groups; prevention of new infections; ensuring care and support for HIV/AIDS infected and affected people; monitoring and evaluation through effective surveillance and research \& establishment of effective \& efficient management system. ${ }^{11,12,13}$

The number of risk populations and prevalence of HIV/AIDS is found increasing every year. Till end of May 2004, in all 3,765 cumulative HIV cases with 747 AIDS cases were reported. However, it is unclear as to what extend this figure reflects the real situation of HIV infections in Nepal. The newly estimated number of persons living with HIV/AIDS is 68, 270 for mid 2003 which represent $0.6 \%$ prevalence among the adult population aged 15-49. By mid 2004, the total population of Nepal is estimated to have reached 24.8 million and the number of People Living with HIV/AIDS should be crossing 70,000 by now. Every year at least 2,000 people in Nepal are infected with HIV; or about 6 Nepalese get infected with HIV every day.

Most epidemiological studies of HIV infection have been conducted in urban areas and little is known about it in rural Nepal. The sex-wise and age-wise distribution of HIV infection may be different because it is not known how representative is this structure for the whole country.

A number of factors determine whether HIV will spread once introduced to a population, including frequency of high risk sex and needle sharing, the proportion of the population engaged in high risk behaviors, the mix of sex partners and the level of other sexually transmitted infections. Although these factors influence HIV transmission individually and in combination, the fact that HIV epidemics consist of multiple, over lapping epidemics evolving on different time scales makes them inherently unpredictable. Even when population groups engaged in sufficient risk behavior to support the growth of an epidemic, it can take surprisingly long time for HIV to reach epidemic levels. High level of needle sharing was documented in early 1990s but HIV infection was negligible. By 2002, 38.4 percent injecting drug users nationally and 68 percent injecting drug users (IDUs) in Kathmandu were infected. The only presence of high levels of risk behavior doesn't guarantee immediate epidemic growth, even though the potential for growth still exists. Frequency of risk behavior and efficiency of the mode of transmission are also important factors. ${ }^{14}$

Future scope or timeline of HIV spread is unpredictable in Nepal. Low rates today are no guarantee of low rates tomorrow. Similarly current national infection levels don't represent a natural limit imposed by behavior patterns. A dynamic society that is undergoing rapid economic and political change also influences the trend of the disease.

The sharply increasing HIV/AIDS trend during recent years in Nepal has forced commitment to work for its prevention. Comprehensive targeted intervention programs such as condom use, behavior change communications, and counseling of population at risk will reflect the success in prevention. In a developing country Nepal, however, sustaining success is a challenge.

\section{CONCLUSION}

The risk populations and HIV/AIDS prevalence have been found sharply increasing after mid 1990s. The latest reported cumulative HIV/AIDS cases as of May 2004 were reported as 747 cases of AIDS and 3,765 cases of HIV infections. Male cases (73 percent) were predominant than female cases (27 percent). Among total HIV/AIDS cases, clients of sex workers (57.8 percent) were predominant followed by injecting drug users (15.6 percent) and sex workers (13.9 percent).

Although sero prevalence of about 0.6 percent is low by the world standards in Nepal the growth trend is alarming. Everyday some 6 Nepalese are infected with HIV and this estimate is still believed to be conservative.

The risk group populations are mostly concentrated in urban and highway areas. The prevalence rate among risk group populations is high in injecting drug users (IDUs) and female sex workers (FSWs). The increasing trend of the infection certainly has given pressure to focus on the use of comprehensive targeted intervention programs in risk group sub-populations.

\section{ACKNOWLEDGEMENTS}

The authors would like to acknowledge Dr. Tirtha Rana, World Bank for her encouragement. Our thanks goes to various institutions particularly to National Center for AIDS and STD Control (NCASC) for providing information on HIV/AIDS and sharing their valuable experiences. 


\section{REFERENCES}

1. South Asian Association for Regional Cooperation Tuberculosis Center (STC). HIV/AIDS in the SAARC Region. June 2003.

2. National Center for AIDS and STD Control (NCASC). National Estimates of Adult HIV Infections, Nepal, 2003. March 2004.

3. WHO/UNAIDS. HIV/AIDS Estimate, 2003.

4. New ERA and Family Health International (FHI). "A Situation Assessment of Injecting Drug Users in Kathmandu Valley", Kathmandu 2002.

5. New ERA, STD/AIDS Counseling and Training Services (SACTS) . HIV/STD Prevalence and Risk Factor among Migrant and Non-migrant Males of Achham District in Far Western Nepal. November. 2002.

6. Poudel $\mathrm{K}$ et al. Mumbai Disease in Far Western Nepal: HIV Infection and Syphilis among Male Migrant Returnees and Nonmigrants. Tropical Medicine and International Health. 2003; Volume 8 (10) : 933-939

7. Sharma M., Karki Y. B. and Joshi AB. June 2004. Optimizing Resource Allocation for HIV Prevention: Background Materials. World Bank, Kathmandu, Nepal.
8. Ministry of Population and Environment (MOPE) and Central Bureau of Statistics (CBS) . Population Projections for Nepal, 2001-2016. December 2003.

9. National Center for AIDS and SID Control (NCASC). Reported HIV/AIDS Cases, May 2004, Kathmandu.

10. National Center for AIDS and STD Control (NCASC) : "Strategic Plan for HIV/AIDS in Nepal, 1997-2001". Teku, Kathmandu, 1997.

11. National Center for AIDS and STD Control (NCASC) . National HIV/AIDS Strategy (2002-2006), Nepal. January 2003.

12. National Center for AIDS and SID Control (NCASC) . National Operational Plan for HIV/AIDS Control, 2003-2007. July 2003, Nepal.

13. National Center for AIDS and SID Control (NCASC) . National Guidelines for Voluntary HIV/AIDS Counseling and Testing. July 2003, Nepal.

14. Monitoring the AIDS Pandemic (MAP). The Status and Trends of HIV/AIDS/STI Epidemics in Asia and the Pacific. 2001. Provisional Report Melboume, Australia.

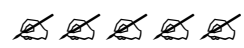

